\title{
Planning Child-Friendly Spaces for Rural Areas in South-Africa
}

\author{
Ma-Rene' Kriel \\ Unit for Environmental Sciences and Management, North-West University, Potchefstroom, South Africa
}

\section{Email address:}

marenekriel@gmail.com

\section{To cite this article:}

Ma-Rene' Kriel. Planning Child-Friendly Spaces for Rural Areas in South-Africa. American Agriculture, Forestry and Fisheries. Special Issue: Planning for Sustainable Communities: Green-Spaces in Rural Areas. Vol. 4, No. 4-1, 2015, pp. 21-32. doi: 10.11648/j.aff.s.2015040401.14

\begin{abstract}
Child-friendly space are not successfully implemented in South Africa due to problems such as urbanization, development pressure, lack of qualitative open spaces and lack of policy and legislation guiding the planning and protection of such spaces. This study explores the possibility of creating qualitative, playful, educational and environmentally preserving open spaces through the creation and provision of child-friendly spaces for children within their surrounding neighbourhood. The priority within rural areas is usually focussed on providing basic facilities and infrastructure, and the provision of qualitative open spaces is often neglected. In this sense, there is no qualitative child-friendly space currently documented or successfully implemented in rural areas in South Africa. This study provides an overview on what is considered as a child-friendly space and the importance to create such spaces. The main challenges faced by rural areas in South Africa in creating child-friendly spaces are explored. Furthermore current planning approaches in providing child-friendly space in rural areas are identified and evaluated. Lastly green guidelines in creating child-friendly spaces are established.
\end{abstract}

Keywords: Child-Friendly Spaces, Open Spaces, Rural Area, Qualitative Green

\section{Introduction}

Open spaces within the South African urban planning context include areas such as parks, boulevards, green belts, buffer strips, lagoons, escarpments and trials [1]. All of these examples, including outdoor play spaces, are components that create an open space system and provide numerous benefits for the public and community in terms of social cohesion, recreational opportunities, health and aesthetic enjoyment [1, 2]. Open spaces such as parks are crucial in developing healthy-communities as it contributes to quality of life by improving, protecting and preserving the quality of the urban environment. Benefits of open spaces and parks include, but are not limited to, visual and aesthetic appealing; places for social interaction, physical and spiritual activity; increase property value; provide shade and protection from natural elements; offers habitat for wildlife and form the image of the local community $[1,2]$. In this sense, open spaces provide a qualitative function within the urban planning context.

According to [1] parks and open spaces are classified in to three levels namely, Level 1: Neighbourhood level, Level 2: Community level and Level 3: Regional level. Neighbourhood level, include playgrounds and tot lots defined as "soft landscape of grass, trees, and planting areas, usually located in a residential setting and detailed and furnished for a variety of active and passive uses". Tot lots and playgrounds are typical neighbourhood level open spaces and serve a population of approximately 2000 residents. Neighbourhood level parks provide both active (sports, play, waling) and passive (sitting, sunbathing, resting) recreation opportunities, and in this sense provide a basis for the development of child-friendly spaces on a neighbourhood level [3].

Community level open spaces serve two to three neighbourhoods and include a broad choice of amenities. Regional level includes open spaces such as Nature Reserves, regional athletic parks, golf courses and campgrounds [3].

Numerous of literature confirms that outdoor play spaces are vital for children's learning and developing stages throughout life [4, 5, and 6]. [3] confirm this statement by emphasizing the importance of play spaces for normal child development. Development includes 1) Physical development (large-muscle or gross motor activities) such as climbing, running and jumping and 2) Intellectual development (manipulative play) where children begin to formulate concepts of action and relationship by energetically manipulating the elements of the environment. Active interaction with the environment is furthermore important for 
children to learn to conserve and respect the natural environment [3, 5].

[7] and [5] stated that outdoor play spaces have the ability to inspire children's imaginations and exploration as well as improve their confidence and connection with friends, family and have a positive effect on community cohesion. It is thus important to ensure adequate child-friendly play spaces within neighbourhoods.

Furthermore [3], [5] and [6] confirms that play is a child's way of learning. Play is complicated, intimate processes which develops and teach children to become socialized. Play is essential for the healthy development of children for their physical, social and cognitive development. It allows children to develop a sense of well-being, improves their interpersonal abilities, develops language skills, establishes creating thinking and involves exploring and problem solving skills.

[5] and [8] states that today's children have fewer opportunities for outdoor play than previous generations. Reasons include urbanization and development pressure where open spaces are used for the development of businesses and housing. Children are a powerful icon of the future. Youth is considered the most critical periods in life in forming an individual's unique relationship with the environment. If children are not able to create their personal relationship with the environment through actively participating with the world around them, their ability to address environmental problems in the future can be threatened [9]. They provide us with a captivating reason to protect the environment, and provide adequate open spaces for outdoor play, thus, through creating child-friendly spaces within open spaces.

From above statements the importance of child-friendly spaces are emphasized. Child-friendly spaces, in context of this research, implying qualitative open spaces developed primarily to be used by children. The concept of child-friendly spaces is thus defined as "a complex multi-dimensional and multi-level concept, referring to settings and environmental structures that provide support to the participation of children and youth in the shaping of their setting, consequently playing a central role in the creation of child-friendly environments in spatial planning" [10].

Literature offers an abundance of definitions defining child-friendly spaces but criteria for creating such spaces are often relatively broad, vague and not easy to implement and only deals with the immediate surrounding environments of children without considering the impact on social, political and historic factors and furthermore do not approach the issue from the child's perspective $[10,11]$. The lack of participation of children throughout the planning proses is the main problem when creating child-friendly spaces. Children's perspective differs from adults and they perceive the natural environment more intensely [10, 12 and 13].

An abundance of literature and authors confirms that numerous problems become major factors in determining the quality of children's outdoor play environments, such as safety and security issues [4, 5]; children's restricted independent mobility [6,13, 14 and 15$]$; and child obesity [13, 15 and 16].
This study is the first step in developing guidelines on planning for and creating improved child-friendly spaces within open areas, especially in rural areas in South Africa. It aims to identify and define essential elements of qualitative child-friendly spaces that support the physical and emotional growth of a child, as well as contribute to sustaining the ecological benefits of the environment.

\section{Child-Friendly Spaces}

\subsection{Defining Child-Friendly Spaces}

There is growing awareness of the importance and benefits of designing healthy, safe places for children [4]. Many aspects define what is considered as child-friendly space and the importance of creating such spaces. A child-friendly space is a safe space created for children where they can actively and passively interact with the environment and socialize with friends through playing and learning simultaneously [4].

According to [10] a child-friendly space can be defined as "a community product developed from local structures beyond the individual level. It comprises a network of places with meaningful activities, where young and old can experiences a sense of belonging whether individually or collectively. The participation of children and youth in the shaping of their setting plays a central role in the creation of child-friendly environments."

The objectives in providing a well-designed child-friendly space are indicated in the following section. The space should provide opportunities for children's physical, cognitive and social development through a wide range of 1) play settings, 2) cultural and racial groups and 3) natural setting and the need for human contact.

1) Play settings [3] implies: Firstly, motor skill development which includes a range of opportunities for children to test their limits and abilities through providing them with a wide range of activities. Secondly, children should be able to make their own decisions about their activities. They should be in control of most or the entire environment. The play space should provide a wide range of decision points that is appropriate to different age and skill levels for the continuing of a present activity, ceasing it, or instigating a new one $[3,4]$. Thirdly, the environments should provide opportunities for learning where children learn to solve problems, manipulate the environment, redesign it and develop their own viewpoints towards the environment. Furthermore the space must provide opportunities for fantasy play where children stimulate their imaginations. The space must not restrict children's imaginative play through being too literal or too abstract.

2) Cultural and racial groups implies that the space must support social development where positive interaction and socializing can take place between different cultural and racial groups and the most important of all a child-friendly space should be fun. Smiling and laughing children are the purest indicator of an effective play space [3, 4].

Child-friendly spaces have two main purposes to provide a 
3) natural setting and the need for human contact. The natural setting must be able to create a rich aesthetic environment where children can enjoy nature, feel comfortable and peaceful. The main motive for a children space it to have direct interaction with the environment where they can observe and socialise when favoured [3].

In conclusion the following characteristics are used to create a successful child-friendly space according to [7] and [5]: Are well located; enables active and healthy lifestyles; make use of natural elements; designing green and promotes sustainability; providing child-friendly transportation options; provides a safe place; provide a wide range of play experiences, risk and challenge opportunities; multi-use and accessible to both disabled and non-disabled children; allow children of different ages to play together.

When considering all above statements the quality of a children-friendly space is more than a piece of play equipment; it's only as rich as the supporting physical and social environments [4].

A child-friendly space should adhere to four main characterisations in order to be successful. This include safety, open space or natural setting, access and sociability and integration [12]. Each of these themes is thoroughly explained in the following division in the context of urban planning provision, focussing on rural areas.

\subsubsection{Safety and Comfort}

A safe environment fosters feeling of security and makes people more willing to engage in outdoor activities according to [12]. A child-friendly space is where children can play safely without fearing the surrounding environment. Safety is a main aspect in creating a child-friendly space and determines whether a play space will be used successfully by the surrounding community. Parental fear are reduced in safe child-friendly spaces and the need for constant supervision is decreased which enables children to explore and discover independently. Children need to be able to play willing in the space without any dangerous hazards and risk but also not totally eliminate the ability to stimulate risk taking opportunities [17].Safety in a child-friendly space especially in rural areas can be improve in terms of planning through providing adequate lightning in and around the space, enhancing the visibility of the play space in all directions for easy supervision, locating emergency public telephones near entrances and providing sufficient drop-off and pick up points away from traffic.

\subsubsection{Natural Open Space}

Research has shown that children prefer to play in natural areas and need access to rich stimulating environments [18]; therefore child-friendly spaces are directly connected and created within the surrounding natural environment. Natural spaces offer sensory stimulation and physical diversity which is critical for childhood experiences outdoors. Child-friendly spaces support greening which refers to the integration of natural elements and processes in a play space. Children's direct social and individual involvement in nature has a positive effect on children's motor skill development, social development, attentiveness and activity level. Integrating the natural environment is a crucial element in creating child-friendly spaces because is forms children's environmental identity and guide their future environmental actions [12, 18, 19 and 20]. The natural environment can be integrated into a play space through providing a wide range of vegetation, trees, shrubs and opportunities for water and sand play.

\subsubsection{Access}

Access is an important factor in creating child-friendly spaces. Children need access to rich appealing environments that are free from unacceptable risk, such as parks to create the opportunity to explore and discover. A children-friendly space must be accessible for all ages and cultures of children. Furthermore it should be accessible for children with disabilities where they can also play and explore freely without limiting their abilities [12, 18 and 19]. Accessible child-friendly spaces can be provided in terms of planning, through locating the space within walking distance and in close proximity of residential areas and schools. Furthermore entrances must be visible, through adequate signage, and accessible for all children disabled and non-disabled.

\subsubsection{Integration and Sociability}

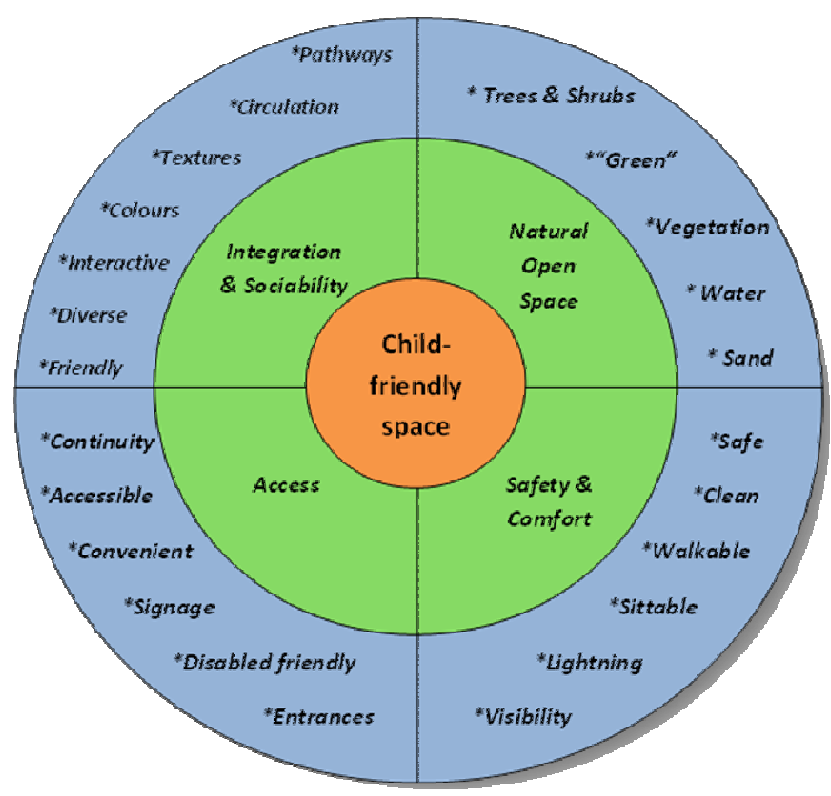

Figure 1. Child-friendly Model.

Source: Own Creation based on [12, 18, 19 and 20]

Child-friendly space need to be created to support different ethnic groups and improve integration in communities. Boys and girls must be able to play freely without discrimination as well as children with disabilities. Integration help children learn gender differences and the ability to see all children as equals no matter the age, size, gender or disabilities $[17,18$ and 19]. Sociability and integration can be improved in terms of planning, through integrating different textures, colors and facilities in the play areas which develops their physical, 
emotional and mental skills. Providing a variety of pathways and seating in the space improves circulation, integration and creates opportunities to socialize. Incorporating water and sand setting in the play area enhances opportunities for socializing and integration. "Fig. 1", illustrates that child-friendly spaces are created according to 4 main themes namely, Natural open spaces, Safety \& comfort, Access and Integration \& sociability. Each of these themes is divided in to sub-themes that integrate the planning of a child-friendly space in rural areas.

\subsection{The Importance of Child-Friendly Spaces}

The importance of child-friendly spaces is examined through the term "play" by many authors such as [3]; [7]; [18]; [20] and [21],thus, consequently the broad definition for the term "play" can be defined as "fun or serious". Through play children explore social, material and imaginary worlds and their connection with them, expanding all the while a supple range of responses to the challenges they stumble upon. By playing, children learn and develop as individuals and as members of the community [18]. Furthermore play is the foundation in forming a child's intellectual, social, physical and emotional skills. For example sand and water play develops logical mathematical thinking, scientific reasoning and rational problem solving. Playing in outdoor environments help children learn through direct concrete material that inspires exploring, manipulation and active engagement [21].

[3] and [7] state that the response of a child to his environment is far more direct and active than an adult's. Children are constantly making discoveries through physically exploring concepts (high and low, near and far, hard and soft, light and dark) that stimulate their imagination and learning abilities. The physical surroundings in which children grow, influence and shape their interactions, development and experience of life into adulthood.

Not only is play important for imaginative skills but risk taking are crucial for children to develop confidence and abilities during childhood. Play stimulated children's minds and help them overcome trauma, fear and stress [7, 18]. Consequently play leads to creating strong supportive communities and helps reduce children and young people in anti-social behavior that may lead to cults and vandalism [3]. Children obtain the following benefits through play according to [18]: Opportunities to enjoy freedom, and exercise choice and control over their actions; Opportunities for testing boundaries and exploring risk; Offers a very wide range of physical, social and intellectual experiences for children; Improves children's independence and self-esteem; Develops social interaction and respect towards others; Improves quality of life; Ensures healthy growth and development; Promotes creativity; Increase knowledge and capacity to learn.

In conclusion children can benefit from play opportunities as highlighted above especially children from stressful circumstances in rural areas. A play area is where children can escape from their fears, poverty and family and experienced freedom and emotional healing. They can improve their communication skills, attitudes, problem solving approaches and even their circumstances in the long term [20].

\subsection{Challenges for Rural Areas and Provision of Child-Friendly Spaces}

South Africa faces many problems due to the apartheid and post-apartheid eras especially in rural areas. The apartheid spatial planning had a few consequences namely cities that are undersized, but sprawling, marginalising, decentralising, planned to obstruct movement and under serviced areas. The post-apartheid settlement planning had its own consequences namely housing-driven settlement planning, de-densification, on-going decentralisation and worsening service levels in sprawling new informal settlements [22]. The main problems include urbanization, poverty, political structure, health, lack of open spaces and environment derogation. The underlying causes of these problems are lack of public awareness, crime, insufficient governance, poor policies, and the lack of knowledge [23].

\subsubsection{Challenges 1: Opportunities}

In South Africa urbanization is mainly caused by the huge supply of job opportunities in cities and the huge demand of job opportunities in rural areas. According to [24] urbanization can be defined as "the shift from rural to an urban society, and involves an increase in the number of people in urban areas during a particular year." Due to the rapid urbanization taking place all over the world, the concept of child-friendly spaces has emerged disputes about urban development from an environmental perspective. Additionally there are no guidelines or frameworks to guide urbanization and results into insufficient open spaces [13]. Rural areas lack open space because the main focus is on housing provision and not open spaces, consequently limiting their opportunities to sufficient open spaces.

\subsubsection{Challenge 2: Independent Mobility}

Rural areas are safety hazards due to poverty, poor street lighting, and degraded urban environments, lack of food, housing and education leading to an increased restriction on children's independent mobility.

The term "children's independent mobility" refers to their freedom to move around without out adult supervision, that is critical for their physical, social, cognitive and emotional development. In modern society, the active, independent mobility of children and young people is becoming increasingly restricted for various reasons such as a lack of safe environments and support bases, limited facilities and development opportunities, increased road traffic have negative consequences for children such as obesity due to lack of exercise, lack of risk taking opportunities, lack of environmental contact and the sense of environmental preservation [6, 7 and 13].

These factors can restrict a child to discover their internal abilities and environmental possibilities as well as fall behind in their social and personal development. Independent 
mobility helps promote children bonding with their peers, how to preserve and interact with the natural and built environments, thus, creates a stronger sense of community and responsibility for the environment, a reduced fear of crime, and increases feelings of isolation during puberty [6, 13, 14 and 15$]$.

Children who are limited in their independent mobility fall behind in the following aspects according to [6]: (1) Social development: Children learn to socialise with friends through playing and meeting new friends in outdoor play spaces as well as learn the ability to adapt to new situations.

(2) Physical development: Sufficient outdoor exercise is not only healthy but a necessity to reduce obesity and health problems in adulthood as well as healthy bone development, posture and balancing skills. (3) Cognitive development: Discovering new things develop children's spatial awareness and their understanding of how the world is structured.

\subsubsection{Challenge 3: Participation}

The improvement of existing park layout and facilities is important to address if repeating past mistakes want to be avoided. Public participation in a specific park design or redesign is essential especially the involvement of children because their needs are not always well represented [3, 19]. The Commissioner for Children and Young People has developed participation guidelines, "Involving Children and Young People: Participation Guidelines', to support the encouragement of practitioners to involve children in the planning and designing of spaces [7]. Children are mostly neglected in land use planning in one of two ways. Firstly, they are given little consideration when it comes to design and secondly, there is lack of planning for children [12].

In rural areas the lack of participation leads to an increase unawareness of environmental preservation and the desire to protect the local environment. According to [12] involving children in the planning process improves integration and gives them a sense of self-worth and a more connected feeling towards the created space. A child-friendly spaces offer recreational opportunities to rural families and provides a liveable place where the people can experience a sense of community [25].

\subsubsection{Challenge 4: Crime and Safety}

The fear of crime and concern for personal safety is consistently within the top issues in South Africa especially in rural areas. Consequently, leading to a change in the ways in which people use public spaces within their communities. According to [3] "fear of crime keeps people off the streets, especially after dark, and out of parks." Safety and security are major factors in determining the quality of children's outdoor play environments. Without being able to take risk children cannot grow to their full potential. Risk taking and challenge have an especially important role in children's play development $[4,5]$.

The fear of crime limits a child opportunity to play in the outdoors. Safe space must be created to enable children to participate in activities with some independence [7]. An approach to address the fear of crime is to consider what the root causes of crime are such as disadvantages, neglected and lack of open spaces and recreation opportunities and discrimination. These causes can be addresses through providing education, job opportunities, economic development, community involvement and efficient planned open spaces in rural areas.

\subsubsection{Challenge 5: Obesity}

Numerous researchers such as [13, 15 and 16] emphases that childhood obesity, due to a lack of exercise, is becoming a significant public health issue all over the world including South Africa. The main reason for above statement is the lack of children's independent mobility and safe, playful child spaces such as parks. In play areas children usually find various play equipment's containing different activities, but rarely opportunities for imaginative play and environmental contact. According to [25] obese people are likely to suffer from high blood pressure, high cholesterol, heart disease, strokes, osteoarthritis and emotional problems such as depression, eating disorders and low self-esteem. Rural areas are restricted to safe play environments and these areas are especially prone to health problems such as obesity.

Children with low-income backgrounds have less if any access to play spaces and are therefore at a disadvantage. Creating child-friendly spaces in rural areas will eliminate all above challenges and help develop healthy and educated children which can improve their quality of life and grant them the opportunity to become more successful in life in adulthood and improve their own circumstance [18].

\subsection{Planning Approaches in Providing Child-Friendly Spaces}

Different approaches to child-friendly space development have the tendency to lead to one of two outcomes 1) a man-made manufactured design or 2) a natural rugged approach. Child-friendly spaces can be divided into two paradigms namely conventional paradigm and conservational paradigm [26]. These paradigms will be discussed and compared to determine which one is more likely to create a successful child-friendly space.

\subsubsection{Conventional Paradigm}

Conventional paradigm focuses on a formal design approach where the equipment is manufactured and firmly designed play equipment. The play area is ordered in a logical manner that can be understood by adults and is not a freely open-minded design where children can explore and fantasise. People are individuals of their one experience and this usually shapes conventional wisdom methods in planning. Adults see playgrounds as asphalts areas were play equipment such as swings and jungle gyms are placed due to the image of their childhood memories, as a result, this perspective is understood as the ideal model of how a children's playground ought to be $[5,26]$.

Play equipment are selected according to catalogues, which appears decent trough an adults perspective and are place in an outdoor space with no effort and ease. The conventional 
paradigm planning approach follows a structured order that is fixed and precise without opportunity for flexibility, consequently leading to an isolated process rather than an integrated whole [27]. However, limiting outdoor spaces with manufactured play equipment is not the ideal planning approach but rather incorporating it with the natural environment which include vegetation, water, sand and wilderness [26].

\subsubsection{Conservational Paradigm}

Conservational paradigm focuses on a more natural and informal design method and can be seen as a discovery play garden rather than a formal structured play area. Children see and experience the natural environment different than adults. Through a child's perspective beauty is seen as rough wilderness rather than an orderly design. In a conservational design approach the space provides openness, variety and openings for manipulation, discovering and experimentation. The conservational paradigm is the shift from a fix structure design approach, as can be seen in the conventional paradigm, to a looser design that includes loose parts such as sand, water and natural manipulative materials. The play space ought to flow from one area to the next, be as flexible and simple as possible and stimulate children's senses and curiosity [26].

\subsection{Summary}

The four main themes contributing in creating child-friendly spaces where identified as, 1) safety and comfort, 2) natural open space, 3) integration and sociality and 4) access. The importance in creating such spaces where linked with physical, emotional and social benefits through the term "play". Furthermore the challenge faced by rural areas where identified such as lack of opportunities, independent mobility, participation, obesity, crime and safety, consequently children in rural areas do not have adequate outdoor play space. Two planning paradigm where identified and discussed namely conventional paradigm which refers to manufacture play equipment, and conservational paradigm which refers to the integration of natural surroundings in the play equipment. In rural areas there are many obstacles to overcome in creating child-friendly spaces these obstacles include the following; lack of children participation in the planning process; parks are not uniquely design according to the community's needs; a quantitative planning approach are followed and not a qualitative planning approach; and lastly the planning process is isolated and not an integrated approach.

\section{Conceptual Framework}

\subsection{Origin of Parks}

The roots of open spaces can be traced back to the 1830's in America where burial grounds were set in pleasant landscaped environments, mostly at the edge of the town. This encouraged the creations of public parks. The New-York's Central Park was the first planned park in America and was designed by the nation's first landscape architect Frederick Law Olmstead in 1858 [2, 3]. According to [28] Olmstead initiated the first concentrated park and recreation movement in the United States. He reasoned that the entire population could not flee to the countryside, but rather bring the rural landscape to the heart of the city and create a pleasing natural setting where people can escape the city. Concurrently, parks were defined as "naturalized passive retreats" and recreation areas as "active sport oriented facilities-playgrounds, hard-surface court areas, team sport fields. " [28]

Eventually open spaces became part of a regional open space system in America and spread to Europe such as Holland, Scandinavia and Germany. The "garden city" movement during 1904 in England, conceived by Sir Ebenezer Howard, was the main objective was to promote the concept of greenbelt, open spaces and parks [2].
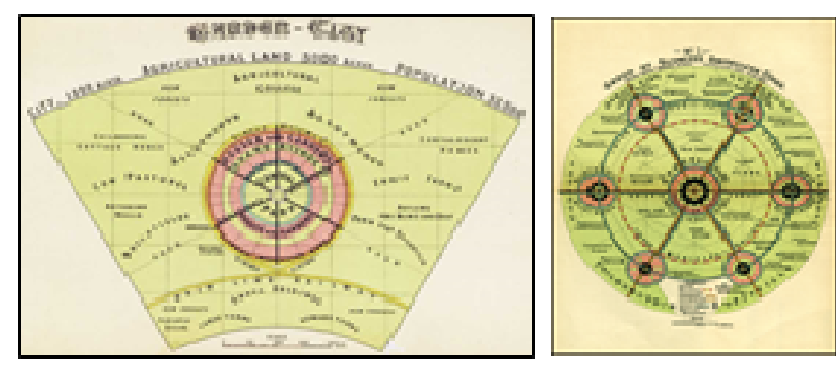

Figure 2. Garden City Model.

Source: [2]

"Fig. 2", illustrates the Garden City proposed by Ebenezer Howard in the 1890's. Howard's concept was for a town of limited size surrounded by agriculture lands. The benefits of rural and urban would be balanced in a self-contained, self-sufficient community. His goal was to devise the ideal plan that would bring urban and rural into harmony with each other. Each garden city will be surrounded with 1,000 acres of urban land and 5,000 acres of agriculture land. The area would support a population of 32,000 people.

From 1946 to 1950 around London 14 New Towns were designated to rehouse the overloud population from the capital. Each of these New Towns had an unusual high proportion of green space. The green spaces were designed as a public amenity and became central features in cities. In the 1970's the public open spaces spread to older towns as well to improve the environmental quality [2].

Today parks are known as "people places" where people actively engage with the environment through observing and socializing in safe, aesthetic spaces that is supported by furnishing and other supporting amenities [3]. Open spaces is ideal in creating child-friendly spaces where children can actively participated in their surrounding natural environment and improve their physical, mental and cognitive development. Open spaces create the opportunity to integrate these spaces into neighborhood settings that is easy accessible for children and supervision is within appropriate distance from surrounding houses. 


\subsection{Green Space Guidelines for Creating Child-Friendly Spaces}

The golden rule in creating an efficient child-friendly space in rural areas is to design the space for the specific location through integrating the surrounding landscape and vegetation as the play settings and nature as possible play materials, consequently it creates a space that can been seen as a discovery play garden according to [5] and [26]. The space must be aesthetic appealing and functional to satisfy the senses of the children. Creating child-friendly spaces is a multidisciplinary and complex task according to [5]; [7] and [28]; therefore guidelines are established in providing successful child-friendly spaces in rural areas. These guidelines are discusses accordingly:

\subsubsection{Location and Size}

The most important factor in a successful play space is the location of the area where children feel safe and want to play. The location of the child-friendly space ought to be away from dangerous roads, noise and pollution and located in an area that are easy accessible for children and visual from all directions [5]. The child-friendly space must be walking distance from surrounding neighborhoods and schools that are easy accessible for all and grant easy supervision for adults. The proposed space must be designed to fit the surrounding attractions and enhance the local character of the environment [28]. Primary features need to be identified on the site and be incorporated into the design such as a structure of an old building, a tree with character or an old sculpture [29]. Inspiration in creating a unique space can be accomplished through historical background on the area or any occurring materials and geographic features [5].

The size of the space depends on the available space in the area and the function of the space. Smaller parks should be small enough to maintain a sense of intimacy, and enable easy visibility and perception, $\pm 25 \mathrm{~m}$ maximum, consequently small parks should be between $450 \mathrm{~m} 2$ and $1000 \mathrm{~m} 2$ in size, with widths of between $15 \mathrm{~m}$ and $25 \mathrm{~m}$, and lengths of between $30 \mathrm{~m}$ and $40 \mathrm{~m}$. The area and dimensions of a play space vary according to the nature of the play equipment, and whether or not the play space is part of a larger soft open space. Play spaces should be small enough to enable easy supervision, $\pm 25 \mathrm{~m}$ maximum, consequently play space should be between $450 \mathrm{~m} 2$ and $1000 \mathrm{~m} 2$ in size, with widths of between $15 \mathrm{~m}$ and $25 \mathrm{~m}$, and lengths of between $30 \mathrm{~m}$ and $40 \mathrm{~m}[28,30]$.

\subsubsection{Creating of a Safe Space}

The creation of a safe space refers to the health and well-being of all children under all circumstances through ensuring that all hazard conditions are removed from the child-friendly spaces [4, 7]. Adequate lightning should be provided throughout the space especially on all pathways and entrances. Fences, barriers and lightning can be used to prevent vandalism. Emergency telephones must be located at entrances and appropriate fencing which surrounds and protects the space [28]. Circulation in the space should be clear with no entrapment zones and clear signage must be provided throughout the space to inform the user of all possible entrances and exits [3]. Furthermore the child-friendly space should be connected to accessible streets and roads that provide routes for walking and cycling and ensure the safety of the children as well as promote their independent mobility [7, 31].

\subsubsection{Creating Accessible Entrances}

The space need to ensure that there are clearly defined entrances which orientate, informs and introduce the users to the specific site. The entrances must be located between transportation areas and where it is easy accessible for children and people with disabilities. The creation of useful accessible entrances is where people can gather, talk and have easy access to the space $[4,7]$. The main aspects of quality entrances in a child-friendly space include the following, according to [4]:

(1) Functionality: The entrances must be located near accessible pathways, drop-off zones, streets and parking areas.

(2) Access: The entrance must encourage a welcoming feeling and provide nonslip walking access pathways that are wide enough for people and children with disabilities.

(3) Drop-off Zones: Entrances is where parents drop-off and pick up their children.

(4) Waiting zones: Entrances are mostly used as waiting zones therefore seating, bicycle stands and shelter against the weather should be provided.

(5) Communication images: The entrances must be visual and attract the user as well as inform them about the information concerning the space and provide them with a map and direction boards $[3,4]$.

\subsubsection{Creating a Variety of Pathways}

Pathways are multi-purpose and provide accessibility to the space and separate different uses within the space. They help users to move between different elements located in the space and improve circulation [28, 29 and 32].The main aspects in creating pathways in a child-friendly space in rural areas are listed below:

(1) Dimensions: Pathways must be wide enough (primary routes 9-10 feet and secondary routes no less than 3 feet) for the appropriate use of the specific pathway and the surface must be accessible, even and non-slip. The slope must be easy accessible for children with disabilities and handrails must be provided on both sides if the slope is steep [4, 33].

(2) Variety: A separate bikeway path should be provided on primary paths. The space should provide variety types of pathways away from the primary path to accommodate different uses such as running, walking and biking [4].

(3) Intersecting and connectivity: Pathways must intersect at some points to support continuity of movement. The hierarchy of pathways can promote movement and help children to understand the play space [28, 29].

(4) Surfaces: Pathway surfaces should be accessible, stable, firm, flat, and slip resistant and raised edges must be provided at hazard areas $[4,32]$. 


\subsubsection{Creating Appropriate Signage}

Signs are a form of communication and provide the users with important information concerning the space as well as provide directions and support of traffic flow within the space [29]. A similar style amongst signs creates familiarity and eliminates confusion, thus, standardization of all signs is proposed [28]. The following aspects are considered when providing signage in a child-friendly space in rural areas:

(1) Types of signage: Signage can be divided into 3 main types: (1) Informational signs: Present general information of the space in words and graphics and is located at the entrances such as rules, closing times and background information. (2) Directional signs: Present directions to different facilities, routes and play areas. (3) Identification signs: Present information indicating specific features such as water or bathroom facilities [4].

(2) Design considerations: Signs must be placed logically and free of obstruction. They must be appropriate heights for children with interesting colors and symbols. Signs can also be used as a learning objective through providing buttons that provide a verbal response. Furthermore signs should support children with all disabilities thus providing words, raised letters, pictures and the appropriate languages spoken in the area (Herrington, 2006:37 \& Moore et al., 1987:57).

\subsubsection{Creating a Variety of Seating Options}

Seating can be used to encourage interaction between people. Seating arrangements can either support or preclude social interaction. Grouped benches facing each other provide opportunity for conversation-making and social interaction while back-to back benches provide opportunities for a more private setting [3]. In a child-friendly space a variety of comfortable seating is essentials for different tasks such as observing, privacy, interaction and waiting. Providing different types of seating also create an interesting aesthetic atmosphere [4, 29].

\subsubsection{Boundaries and Fencing Considerations}

Fences are used in a child-friendly space to define, protect, separate and create activity settings. Fences can also be used to direct pedestrian movement and protect the surrounding vegetation. According to [4] and [5] the following design considerations must be taken into account when providing fencing in a child-friendly space in rural areas:

(1) Barriers: Fencing can be designed as barriers to protect vegetation and provide play elements. The main objective of the barrier is not to keep the children out the vegetation but rather reduce the impact so that the plants can recover and survive. Fencing is also used to define intimate social areas and provide privacy away from activities [4].

(2) Barriers against weather conditions: Barriers can be used to protect children against harsh sunlight and strong, cold winds [29].

(3) Aesthetic appearance: Fences and barriers must be attractive and not obstruct sight. Vegetation, groundcovers and vines can be used to make fencing attractive.

(4) Play setting: Providing fencing with peep holes and interesting colors and textures an attractive play settings for children [4].

\subsubsection{Creating Child-Friendly Play Equipment}

Play settings stimulate large muscle development and supports movement, social interaction as well as fantasy play which stimulate children's mental development. Equipment settings should be multipurpose and support creativity and coordination development [3, 4 and 33]. A well designed play space ensures play equipment where disabled and non-disabled children can play together. The play space should have a stimulating layout and be aesthetic appealing through providing imaginative equipment [29]. The following criteria are used in choosing and creating play equipment for children:

(1) Hazard versus challenge: Children use equipment in all possible ways and the equipment must be designed to incorporate safety to eliminate dangerous hazards and provide different levels of challenges. A good play setting allows children to take risk and challenges them through swinging, jumping and climbing [4, 20 and 33].

(2) Separate play areas: Separate play areas should be provided for different age groups especially for children less than three years of age. Barriers can be provided to protect smaller and younger children. Well-designed play areas have different degrees of challenges, which enabled integration of different age groups and prevent physical obstructions [4].

(3) Options: Providing children with a variety range of play settings stimulates a wide range of activities and ensures that that play area are used frequently such as climbing, swinging, crawling, bouncing, jumping, balancing and sliding [20, 29 and 33].

(4) Sensory variety: Play equipment need to stimulate all the senses of a child through providing opportunities for touch such as different textures sand, water and vegetation, fragrant plant materials for smell and colorful play equipment that are visually stimulating. Children usually respond best to bright cheerful primary colors [4, 5, 28 and 29].

(5) Movement, linkage and flow: Play equipment should support movement and linkage between different play equipment and provide different levels of play. Play equipment must be visually understandable for children with many ways to get on and off. Orientation can be supported through different colors, textures and shapes [3, 5 and 28].

(6) Disabilities: Children in wheelchairs must be able to access the play equipment through providing wheelchair entrances or raised play settings as well as handle bars to support body weight [3, 4 and 33].

(7) Themes: Thematic elements provides opportunities and encourage fantasy play through creating slides that look like rocket ships, climbing areas as castles and fixed in pieces such as a steering wheel [4, 29].

(8) Slides and swings: The play area should include different heights of slides to accommodate all ages of children. Access for children with disabilities to the slides can be created through providing stairs alongside the slide. Slides can contribute in creating a play area with variety and challenge such as slide designs that includes waves, spirals and tunnels 
[3]. Swings should be situated away from other equipment and tire swings make it accessible for children with disabilities. Furthermore swings ought to include safety straps to accommodate all ages of children as well as children in wheelchairs [3].

(9) Climbers and balancing equipment: Play structures should include a form of climbing to develop upper body strength and create challenge opportunities. Balance equipment such as rocks, logs and chains can be used to link different play equipment and areas with each other and is vital important for balancing and coordination development in children [3, 5 and 29].

(10) Surfacing under play equipment: The best impact absorbing surfacing under high zone fall areas include the following: (1) Rubber: Chopped compact tire is the best impact absorbing surface to use under play equipment due to its ability to spread outside its containment barrier, thus, children are less likely to obtain injuries. (2) Sand: Sand is the second best impact absorbing surface and is most frequently used as fall cushioning due to the ability to deform to the shape of the falling child. Sand is also must cheaper than rubber absorbing products.(3) Gras: Gras is not recommend as surfacing under equipment with a high fall zone risk because grass is prone to minor injuries and is preferred on open areas for chasing and rolling games $[3,5]$.

\subsubsection{Supporting Amenities and Lightning}

In a child-friendly space the provision of supporting amenities are essential, such as toilet facilities, and coverage facilities against rainfall and strong winds. Other facilities may include storage area for play equipment and management of the space [3]. Adequate lightning are an essential factor in creating an efficient child-friendly space in rural areas, consequently providing protection and peace of mind. Lightning can be used for the following:

(1) Safety lightning: Provides necessary lightning for people during night time to provide safety against crime.

(2) Security lightning: Provides a degree of protection to the property against vandalism and crime.

(3) Aesthetic lightning: Is used to enhance the beauty of a visual element such as a fountain or statue [32].

\subsubsection{Supporting Vegetation and Trees in Child-Friendly Areas}

People-plant interaction is important in creating a rich child-friendly space where users can make close contact with vegetation such as groundcovers, shrubs and trees. Vegetation and trees create a wide range of play activities such as tree climbing, hide and seek games, exploring, discovering, and manipulative play, collecting and touching of plants. Leaves, flowers, fruits, seeds, sticks and nuts stimulate a variety of senses and imaginative responses in children [5, 20 and 29]. Trees are used as barriers against cold winds, harsh sunlight and rainy days, as well as provides a shady play area and attracts wildlife and birds, consequently creates opportunities for people-wildlife interaction $[3,5]$.

Vegetation marks the passing of seasons and develops children sense of time as well as creates a pleasant atmosphere of textures, smells and colors'. Children in wheelchairs can enjoy vegetation through creating raised planting areas. Plants chosen must be fast growing, easy to maintain, resilient and comfortable to touch and does not irritate the skin [5]. Child-friendly spaces include plants that eliminate poisoning and injuries and trees that can endure tree climbing activities which creates a sense of achievement amongst children [3]. Trees are chosen according to their rooting pattern, water requirements, climbing durability and growing behavior [2].

Vegetation can be used for the following in a child-friendly space in rural areas [28]: To form spaces and shapes; To direct circulation; To provide detail interest; To supply shade and protection against the weather; To buffer odors and noise; To provide sensory stimulation; To provide opportunities for learning.

\subsubsection{Creating a Garden or Vegetable Setting}

Garden or vegetable settings are a best way of enabling children to interact with each other and nature. They learn about the ecological cycle, how to preserve the environment and it stimulates the cooperative work between children. Raised beds create easy access for children in wheelchairs and protect plants against direct impact and pests. Children can experience different taste and learn more about different kinds of fruit and vegetables, thus, encouraging them to eat healthy. Vegetable gardens are a great way in involving the community and promote interaction between people; furthermore it also provides the community with a source of income if the fruits and vegetables are harvest and sold [4, 5 and 31].

\subsubsection{Promoting Environmental Sustainability}

A good play space can be designed through using recycled materials and incorporating the natural environment as far as possible to ensure sustainability. As mentioned above the integration of trees and vegetation support environmental sustainability as well as the provision of a vegetable garden setting. Fallen leaves, twigs and grass cuttings can be reworked back into the environment to preserve the ecological cycle and it provides additional play opportunities [3]. Furthermore the play space should provide decent recycle bins which sort's plastic, cans and paper to create awareness of sustainability amongst the children and this is a fun meaningful way to educate them. The recycle bins can be designed in an interesting way with capturing color's to gain children's attention [32]. Not only will the play space support sustainability but the desire to protect the environment is established amongst children and they will preserve the environment over the long-term [5].

\subsubsection{Creating a Sand Setting}

Sand is multi-functional and can serve as play material and safety surfacing as well as improve the quality of the play space. Sand areas in child-friendly spaces should be located near water play and paths where it is easy accessible for children with disabilities [5, 29]. Furthermore the sand play areas are best located near or under trees for shade in the summer and protection against cold winds during the winter [3]. The following criteria area important to take in 
consideration when creating sand plays areas in child -friendly spaces in rural areas:

(1) Playability: The type of sand should contain a small grain size which makes it easier to mold and sculpture with as well as have a low dust content to prevent unwanted allergies.

(2) Design considerations: The sand areas must be located near water play and separated from active play equipment, furthermore, have multi-level sand tables and access points to accommodate disabled and nondisabled children. The sand pits should be between 18-24 inches and have a 2-3\% slope to prevent sand from falling out. Providing a form of table setting in the sand play area provides children the opportunity to sculpt and mold forms easier [3, 4].

(3) Vegetation and water: Incorporating vegetation and water play with sand play settings enhances the range of fantasy play and is essential for good sand play settings [3, 29].

\subsubsection{Creating a Water Setting}

Water play creates a multi-sensory function such as sounds, textures and a substantial aesthetic dimension. Children are excited and relaxed through water play and it enables them to have physical contact with water which can be incorporated with sand play to provide a more appealing play setting $[5,29]$. Shallow pools and sprays are used in child-friendly spaces for children to cool-off during the hot summer months. Children can interact and experiment with water play through observing materials that sink and float, thus, supporting the development of their intellectual skills. Water play can be integrated in a child-friendly space through forms such as streams, drinking fountains, spray pools, sprinklers and water tables [3, 4]. The following criteria are used in creating a water play setting:
(1) Design considerations: Water and sand play areas should be located next to each other away from active play equipment and under trees for shelter against wind and the hot summer days. Seating should be provided for adult supervision and the water setting must be easy visible from all directions. Water depth must be carefully considered to eliminate drowning risks therefore spray pools, drinking fountains and water tables are best recommended. Shallow ponds can be integrated with stepping stones and bridges for close contact with the water and is fascinating for children [3, $5]$.

(2) Circulation: Water must circulate to eliminate health risk and provide a relaxing atmosphere this can be accomplish through running water tables, water pumps and wandering streams. The water play setting should be connected to the public water supply if natural rainfall is insufficient in the area $[3,32]$.

(3) Sprays: Spray areas are preferable to standing water and uses less water supply. A fine spray is best comfortable for all weather conditions. Spray areas should contain non-slip surfaces and different spray types can be used to create an attractive atmosphere such as sprinkles, hoses and nozzles [3].

(4) Fountains: Drinking fountains can be integrated as primary aesthetic features in a child-friendly space and provide drinkable water for all. The fountain should be located where it is convenient for most children and the appropriate height. Each fountain should be equipped to provide clean water in a sanitary manner [32].

(5) Water tables: Water tables make access to water possible for children in wheelchairs and create an appealing feature [3].

Table 1. Comparative summary of guidelines in creating a child-friendly space.

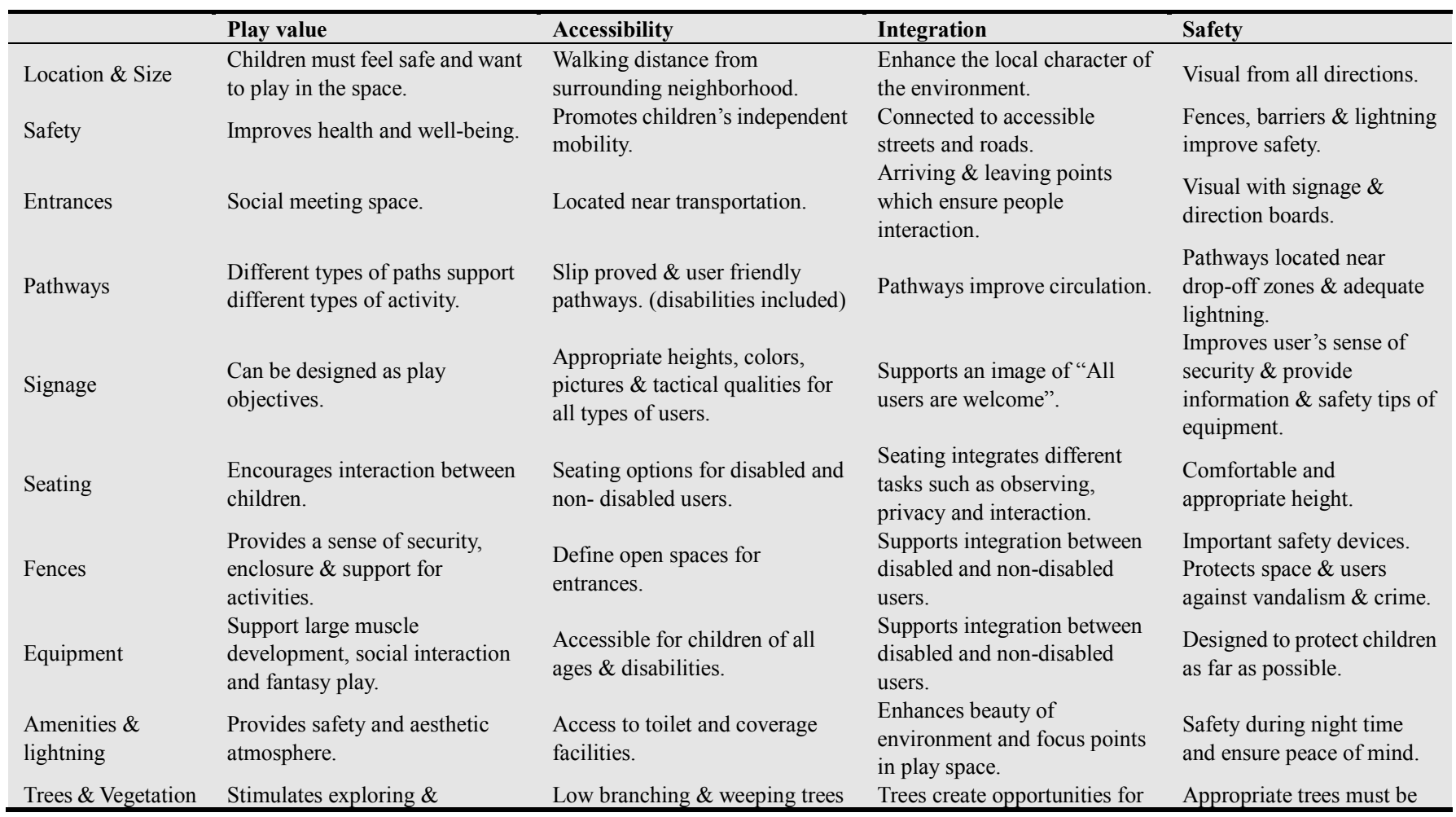




\begin{tabular}{|c|c|c|c|c|}
\hline & Play value & Accessibility & Integration & Safety \\
\hline & $\begin{array}{l}\text { discovery behavior. Encourages } \\
\text { fantasy \& imaginative play. Tree } \\
\text { climbing develops upper body } \\
\text { strength. }\end{array}$ & $\begin{array}{l}\text { are accessible for children in } \\
\text { wheelchairs. Vegetation can be } \\
\text { integrated into accessible } \\
\text { settings for all. }\end{array}$ & $\begin{array}{l}\text { interactive play between } \\
\text { children. Vegetation is the } \\
\text { most important element for } \\
\text { integration as it can be shared } \\
\text { and loved by all. }\end{array}$ & $\begin{array}{l}\text { selected which support tree } \\
\text { climbing activities. All } \\
\text { harmful and poisonous } \\
\text { vegetation must be } \\
\text { eliminated. }\end{array}$ \\
\hline $\begin{array}{l}\text { Garden or } \\
\text { vegetable setting }\end{array}$ & $\begin{array}{l}\text { Improves social interaction, fine } \\
\text { motor skills development \& } \\
\text { sensory stimulation. }\end{array}$ & $\begin{array}{l}\text { Raised beds area accessible for } \\
\text { all users. }\end{array}$ & $\begin{array}{l}\text { Gardening is a group activity } \\
\text { that improves integration and } \\
\text { community involvement. }\end{array}$ & $\begin{array}{l}\text { Gardens need to be raised or } \\
\text { enclosed where direct } \\
\text { impact is minimized. }\end{array}$ \\
\hline Sand play setting & $\begin{array}{l}\text { Excellent medium for creative } \\
\text { play \& social interaction. }\end{array}$ & $\begin{array}{l}\text { Multi- level sand areas make it } \\
\text { accessible for disabled \& } \\
\text { non-disabled users. }\end{array}$ & $\begin{array}{l}\text { Supports \& motivates } \\
\text { interactive play. }\end{array}$ & $\begin{array}{l}\text { Is used as safety fall surface } \\
\text { material. }\end{array}$ \\
\hline Water play setting & $\begin{array}{l}\text { Multisensory character includes } \\
\text { sounds \& textures. Excites \& } \\
\text { relaxes children. }\end{array}$ & $\begin{array}{l}\text { Multi- level sand areas make it } \\
\text { accessible for disabled \& } \\
\text { non-disabled users. }\end{array}$ & $\begin{array}{l}\text { Supports \& motivates } \\
\text { interactive play. }\end{array}$ & $\begin{array}{l}\text { Shallow water and sprays } \\
\text { are easy accessible and } \\
\text { safer \& circulation } \\
\text { improves the water quality. }\end{array}$ \\
\hline
\end{tabular}

Source: Own Creation

\section{Conclusion}

Creating child-friendly spaces is a multidisciplinary and complex task. The golden rule in creating an efficient child-friendly space in rural areas is to design the space for the specific location through integrating the surrounding landscape and vegetation as the play settings and nature as possible play materials. The space should be aesthetic appealing and functional to satisfy the senses of the children. These issues should be incorporated in the spatial planning process. The main challenges, cross reference to Section 2.3, faced by rural areas in South Africa in creating child-friendly spaces were explored and was identified as a lack of opportunities, independent mobility, participation, obesity, crime and safety, consequently children in rural areas do not have adequate outdoor play space. The current planning approaches were identified and describe namely as, conventional paradigm which refers to manufacture play equipment, and conservational paradigm which refers to the integration of natural surroundings in the play equipment.

The conclusion was made that a conservational paradigm approach in spatial planning needs to be pursued to create an effective and qualitative well-designed child-friendly space in rural areas. The importance in creating such spaces where linked with physical, emotional and social benefits through the term "play". A child-friendly space should adhere to four main characterizations in order to be successful, namely 1 ) safety and comfort, 2) natural open space, 3) integration and sociality and 4) access, cross reference to Figure 1. Children can benefit from play opportunities especially children from stressful circumstances in rural areas. A play area is where children can escape from their fears, poverty and family and experienced freedom and emotional healing. Children with low-income backgrounds have less if any access to play spaces and are therefore at a disadvantage. Creating child-friendly spaces in rural areas will eliminate challenges and help develop healthy and educated children which can improve their quality of life and grant them the opportunity to become more successful in life. Children don't realize they need recreation and this leads to inappropriate behavior such as crime, vandalism, cults and drug abuse due to being bored and not using their free time healthy.

Green guidelines in creating child-friendly spaces were established and the guidelines were summarized into a guiding framework, Table 1, which can be used to evaluated future child-friendly spaces in rural areas. This study was the first step in developing guidelines on planning for and creating improved child-friendly spaces within open areas, especially in rural areas in South Africa

\section{Acknowledgements}

I would like to thank the God for giving me the knowledge and perseverance to complete this project and Dr. E. J. Cilliers, for her mentorship, support and guidance.

\section{Nomenclature}

CCYP- Commissioner for Children and Young People

\section{References}

[1] J. Harper, "Planning for Recreation and Parks Facilities: Predesign Process, Principles, and Strategies," Pennsylvania: Venture, pp. 2-180, 2009.

[2] B. Clouston and K. Stansfield, "Trees in Towns: Maintenance and management," London: Architectural Press, pp.8-133, 1981.

[3] C.C. Marcus and C. Francis, "People Places: Design Guidelines for Urban Open Spaces," 2nd ed., New York: Wiley, pp.5-293, 1998.

[4] R. Moore, S. Goltsman, and D. Iacofano, "Play for all: Guidelines,” Berkeley: MIG Communications, pp.6-155, 1987.

[5] A. Shackell, "Design for Play: A guide to creating successful play spaces," England, pp.1-130, 2008.

[6] J. Zomervrucht, "Gradually grow to cycle: Experiences with a child-friendly public space,”Netherlands, pp.8-17, 2005.

[7] CCYP, "Building spaces and places for children and young people," Australia, pp.4-19, 2011. 
[8] G. Woolcock, B. Gleeson, and B. Randolph, "Urban research and child-friendly cities: A new Australian outline," $2^{\text {nd }}$ ed., pp.177-192, 2010.

[9] G. Thomas and G. Thompson, "A child's place: Why environment matters to children," Green Alliance / Demos report, pp.3-23, 2004.

[10] L. Horelli, "Constructing a theoretical framework for environmental child-friendliness. Children, Youth and Environments," $4^{\text {th }}$ ed., 2007.

[11] S. Schulze and Moneti, "The child friendly cities initiative. Proceedings of the Institution of Civil Engineers," $2^{\text {nd }}$ ed., pp.77-81, 2007.

[12] C. McAllister, "Child Friendly Cities and Land Use Planning: Implications for children's health,” 3rd ed., pp.47-56, 2008.

[13] M. Nordström, "Child-friendly cities - sustainable cities," Sweden, pp.44-45, 2004.

[14] A. Carver, A.F. Timperio, and D.A. Crawford, "Young and free? A study of independent mobility among urban and rural dwelling Australian children," 2012.

[15] M. Huby and J. Bradshaw, "A Review of the environmental dimension of children and young people's well-being," Heslington, pp.4-39, 2008.

[16] A. Abolahrar, "Freedom Play Sticks for Play Spaces," Gothenburg, pp.2-24, 2011.

[17] S. Munoz, "Children in the Outdoors," Scotland: SDRC, pp.5-24, 2009.

[18] PLAYLINK, "Best Play: What play provision should do for children," Scotland: Sutcliffe Play, pp.1-9, 2000.

[19] DTLR, "Improving Urban Parks, Play Areas and Open Spaces," London, pp.8-189, 2002.

[20] A. Parsons, "Young Children and Nature: Outdoor Play and Development, Experiences Fostering Environmental Consciousness, And the Implications on Playground Design," Virginia, pp.4-74, 2011.
[21] J. Hewes, "Let the children play: Nature's answer to early learning," Canada, pp.2-6, 2006.

[22] S. Campbell, "Green Cities, Growing Cities, Just Cities? Urban Planning and the Contradictions of Sustainable Development," Journal of the American Planning Association, pp.1-7, 1996.

[23] L.B. Sohn, "Stockholm Declaration on the Human Environment, 1973.

[24] K. Nsiah-Gyabaah, "Urbanisation Processes- Environmental and Health effects in Africa," pp.1-2, 2004.

[25] P.M. Sherer, "The Benefits of Parks: Why America Needs More City Parks and Open Space," San Francisco: The Trust for Public land, pp.6-22, 2003.

[26] R. White and V. Stoecklin, "Children's Outdoor Play \& Learning Environments: Returning to Nature," White Hutchinson Leisure \& Learning Group: Kansas, pp.1-8, 1998.

[27] M. Jansson, "Management and Use of Public Outdoor Playgrounds,"Alnarp: SLU Repro, pp.9-78, 2009

[28] A.B. Rutledge, "Anatomy of a Park," NewYork:McGraw-Hill, pp.1-146, 1971

[29] Department of Housing, "Guidelines for Human Settlement Planning and Design," 1 ste ed., vol. 1. Pretoria: CSIR Building and Construction Technology, pp.13-278, 2000.

[30] DEMOS, “A child's place: why environment matters to children," London, pp.3-21, 2004.

[31] M.L. Christiansen, "Park Planning handbook," New York: Wiley, pp. 1-219, 1977.

[32] KOMPAN, "Play for All: The newest developments in universal design, accessibility and inclusion in playgrounds," pp.2-11, 2007.

[33] S.Herrington, "CHILD: Seven Cs an Informational guide to young children's outdoor play spaces," $2^{\text {nd }}$ ed., pp.1-59, 2006. 